Daimon. Revista Internacional de Filosofía, Suplemento 5 (2016), 555-562

ISSN: 1130-0507 (papel) y 1989-4651 (electrónico)

http://dx.doi.org/10.6018/daimon/269081

\title{
El lenguaje del cuerpo y razón de amor en María Zambrano
}

\author{
The language of the body and the reason of love \\ in Maria Zambrano
}

JUANA SÁNCHEZ-GEY VENEGAS*

Resumen: La filosofía del siglo XX encontró en autores como Bergson, Husserl, Merleau-Ponty o Gabriel Marcel reflexiones muy interesantes acerca del cuerpo, sin embargo nosotros queremos atender a la filosofía española contemporánea, puesto que pensamos que esta filosofía se ha centrado siempre en un realismo de la razón en apertura a la vida, razón integradora, que pone en diálogo el cuerpo y la trascendencia. Nos centraremos en María Zambrano y, siendo su obra extensa, nos vamos a limitar casi a sus primeros artículos, con el propósito de continuar esta aportación que aparece en su obra. En efecto, toda su obra y su vida tratan de la escucha de esta vivencia humana que consiste en la unidad relacional del cuerpo y algo más, que es el alma. Así sus lecturas órficas y de la mística, en su sentido religioso, le permiten atender una y otra vez a esta entrañada relación humana y decantarse, al mismo tiempo, por el ejercicio de la libertad como dominio de lo menos hacia lo más.

Palabras claves: cuerpo, trascendencia, alma, espíritu, razón poética, razón de amor.

\begin{abstract}
The philosophy of the 20th century encountered very interesting reflections on the body in authors like Bergson, Husserl, MerleauPonty or Gabriel Marcel. However, we want to deal with the contemporary Spanish philosophy, because we think that this philosophy always centered in a realism of the reason and an openness towards life, integrated reason that brings the body and the transcendence into dialogue. We will focus on María Zambrano and due to her extensive work; we will mostly limit us to her first articles with the aim to continue this contribution that appears in her work. In fact, all her work and life are about listening to this human experience that consists in the relational unity of the body and something more which is the soul. In this way her orphic lectures and lectures of mystic, in the religious sense, allow her to deal repeatedly with this involved human relation and at the same time lean towards the exercise of the liberty as a power of the less towards the more.

Keywords: body, transcendence, soul, spirit, reason poetry, reason of love.
\end{abstract}

\section{Introducción}

La filosofía del siglo XX encontró en autores como Bergson, Husserl, Merleau-Ponty o Gabriel Marcel reflexiones muy interesantes acerca del cuerpo, pero nosotros queremos

Fecha de recepción: 21/06/2016. Fecha de aceptación: 06/09/2016.

* Universidad Autónoma de Madrid. Profesora Titular de Filosofía. Historia de la Filosofía española e iberoamericana. Publicaciones recientes: María Zambrano (2016), Sinergia, Madrid; Diccionario de filósofos españoles contemporáneos (2015), Montecarmelo, Burgos. juana.sanchez-gey@uam.es 
atender a la filosofía española contemporánea, puesto que pensamos que este pensamiento se ha centrado siempre en un realismo de la razón que se presenta en la apertura a la vida, y se ha expresado mediante una razón integradora, que pone en diálogo el cuerpo y la trascendencia.

\section{María Zambrano: razón de amor}

Nuestra primera reflexión la centraremos en María Zambrano y, siendo su obra extensa, nos vamos a limitar casi a sus primeros artículos, con el propósito de continuar esta aportación que aparece en toda su obra. En efecto, toda su reflexión y su vida tratan de la escucha de esta vivencia humana que consiste en la unidad relacional del cuerpo y algo más, que es el alma y es el espíritu. Así sus lecturas órficas y la de la mística, en su sentido religioso, le permite atender una y otra vez a esta entrañada relación humana y decantarse, al mismo tiempo, por el ejercicio de la libertad como dominio de lo menos hacia lo más. En unas palabras escritas por José Luis Abellán, el profesor refiere una conversación con María Zambrano, aún en el exilio. Al terminar ella se despide así:

¡ Llevátela, llévate mi voz! Por ella quiero ser recordada. La Voz y la Palabra, eso es lo que quiero que quede mío en el mundo, cuando ya me haya ido ${ }^{1}$.

Es así, que cuando escribe La Metáfora del corazón, el corazón o la voz o la palabra es la representación máxima "de todas las entrañas de la vida, la entraña donde todas encuentran su unidad definitiva" 2 . La filosofía de María constituye una reflexión sobre la condición humana, algunos la han denominado "metafísica experiencial" (Juan Fernando Ortega Muñoz) o también “Antropología existencial” (Mercedes Gómez Blesa), pero siempre se ha dicho que es una filosofía pegada a la vivencia del ser o de la criatura humana. Y acerca de la existencia del hombre, en su sentido genérico, probablemente la definición que se cita de forma repetida es ésta:

\section{El ser humano es aquel que padece su propia trascendencia ${ }^{3}$.}

En esta definición, se unen entrañadamente, cuerpo y trascendencia; pasión y razón, padecimiento y amor. Porque María Zambrano afirma que lo sagrado anida en nuestras entrañas. Y este vivir lo sagrado en nuestro interior permite al hombre ser feliz y también padecer sufrimiento. Pues el cuerpo es el eco de la vivencia y el espíritu habla a través de los sentidos exteriores e interiores. Todo ello queda escrito en el mismo título de uno de sus primeros artículos Hacia un saber sobre el alma donde se refleja su aportación a la filosofía como reflexión programática. Su propuesta consiste en una búsqueda de la verdad para proponerla a los hombres de su tiempo, en la que filosofía y amor van unidos, razón y acción.

1 Abellán, J. L. María Zambrano. Una pensadora de nuestro tiempo, Barcelona, Antrhopos, 2006, p. 114.

2 Zambrano, M. La metáfora del corazón (1944) en Hacia un saber sobre el alma, Madrid, Alianza Editorial, 1986, p. 54.

3 Zambrano, M. "El Libro de Job y el pájaro" en El Hombre y lo divino, Siruela 1991, Madrid, p. 359; El sueño creador, Madrid, Turner, 1986, p. 53; Los sueños y el tiempo, Madrid, Siruela, 1992, p. 5 y 9 y M-447, p. 3. 
En una reflexión original, alejada de las palabras hueras que se enroscan en sí mismas, y propone al mismo tiempo el sentido sagrado y cristiano de su pensamiento:

Y como eje de todo, la idea cristiana del hombre como un ser que muere y ama, que muere con la muerte y se salva con el amor ${ }^{4}$.

En sus primeros artículos Zambrano, como hemos visto, expone su propia visión de la filosofía, aquellos senderos que transita: la pregunta por la condición humana en su realidad más concreta que es el cuerpo, su sentir y la trascendencia. Saber de experiencia, dirá en no pocas ocasiones, porque busca explicarse y explicar la vivencia concreta que se siente en el cuerpo y en alma.

Es el hombre, el hombre íntegro, en carne y hueso, en alma y espíritu, en arrolladora presencia que todo lo penetra. El hombre entero, verdadero 5 .

En su conocido artículo Por qué se escribe (1934) dice que el vivir requiere expresarse, pues es preciso comunicar los sentimientos más vivenciales. En Por qué se escribe y en La confesión (1943) defiende especialmente la necesidad comunicativa del ser humano que es razón unitiva entre su cuerpo y la trascendencia, porque toda vida humana exige nacimiento y conversión ${ }^{6}$. La vida humana, que es corpórea y espiritual busca encontrar la unión entre ambas, y explicarse en su primer sentir, que es del alma, mas todavía en un cuerpo que padece, sufre y se turba ${ }^{7}$, esto es lo que el alma siente, así el lenguaje del cuerpo se abre a una razón de amor, como ya dijera en La Guerra, de Antonio Machado que la "Razón poética es de honda raíz de amor"s.

En realidad el lenguaje del cuerpo es un Saber de las entrañas y con ello se nos recuerda, de nuevo, la relación del cuerpo, que es percepción de lo interior y de la intimidad, lo que nos es propio, pero nunca una realidad cerrada sobre sí misma, sino que está abierta al alma, que es "sentir de las entrañas" y a algo más, que es lo sagrado.

Ser hombre, cobrar existencia humana, consiste en el adentrarse del alma en el hombre, y con ella el amor. Y este adentramiento es padecer ${ }^{9}$.

María Zambrano se enmarca en una filosofía, la filosofía española alentada por un pensar la realidad para compenetrarse y conocer el alma, atenta siempre desde un pensamiento relacional a ese conocimiento integrador que relaciona el cuerpo y el alma, en apertura con

4 Zambrano, M. "Hacia un saber sobre el alma", en Hacia un saber sobre el alma, Alianza Editorial, Madrid 1986, p. 21.

5 Zambrano, M. Pensamiento y poesía en la vida española, Madrid, Ed. Endymion, 1987, p. 37.

6 "Todo el que hace una confesión es en espera de recobrar algún paraíso perdido" Zambrano, M "La Confesión como género literario y como método" en Antología, selección de textos, Suplementos Anthropos, Revista de Documentación Científica, marzo-abril, 1987, Barcelona p. 65.

7 “Cuándo dejaré de escribir, me pregunto, cuándo, Señor, dejaré de temblar”. María Zambrano en Prólogo (1985) a Senderos, Barcelona, Anthropos, 1986, p. 9.

8 Zambrano, M “La Guerra, de Antonio Machado" en Senderos, Barcelona, Anthropos, 1986, p.68.

9 Zambrano, M. "Para una historia del amor" en El hombre y lo divino, op.cit., p. 254. 
el Creador. Cuando se refiere al ser humano, como en la Tumba de Antígona le denomina criatura ${ }^{10} \mathrm{y}$, en otras muchas ocasiones, así mismo en Pensamiento y Poesía en la Vida española dice: "El ser, la criatura, que todo español no pervertido lleva dentro, en sus entrañas, debajo de su ser histórico, debajo de sus ideas"11. Lo sobresaliente de esta forma "criatura" o de esta denominación zambraniana es lo que significa. Ser criatura es una dimensión que evoca la del Creador y apela a una relación genética, constitutiva, familiar, esta dimensión afecta a todo el ser. De ahí que desde su reflexión filosófica acerca de la unidad entre filosofía, poesía y religión, Zambrano subraye la mística y, de nuevo, señala la peculiaridad de la mística española

... en esa mística no está como en la nuestra la misericordia; no está tampoco la presencia maravillosa del mundo y sus criaturas, como en San Juan de la Cruz; no está la carne, la materia humana con sus palpitaciones, la materia misma de las cosas, consideradas materialmente como en Santa Teresa ${ }^{12}$.

La criatura hace relación al Creador, también a la carne y al palpitar humano como testigo de una vida humana que es siempre sagrada, por ello cuando Zambrano habla de la mística española, frente "a la del norte" la percibe más concreta, más humanizada y, lo veremos más adelante, mas filial. La criatura hace relación a la paternidad, a la carne o al cuerpo y a las cosas. Pocos filósofos han mantenido ese diálogo, el lenguaje del cuerpo que habla y se relaciona intrínsecamente con el alma, y ésta le responde dando razón de amor.

María Zambrano habla de la necesidad de la asunción de nuestra condición como seres corporéos.

Solo cuando el hombre acepta íntegramente su propio ser comienza a vivir por entero $^{13}$.

Y este ser persona se da en la vida, en un cuerpo y en una psique ${ }^{14}$.

María Zambrano expone repetidamente que ser hombre sólo se alcanza desde la aceptación de sí mismo: "No se es hombre simplemente por haber nacido hombre, sino cuando se asume el serlo"15, ahora bien hablar de aceptación es hablar de la conciencia, que asume la realidad del cuerpo y alma intrínsecamente unidos. Y, ésta es la interpretación zambraniana de la condición humana en su bello y extenso artículo El Libro de Job y el pájaro, puesto que la queja de Job no proviene de la pérdidas materiales sino de su falta de conciencia, pues la verdadera condición humana reside en el binomio vivir es conocer y conocer es propio

10 "el filósofo ha de buscar siempre el estado inicial en que se es sin más criatura" la Tumba de Antígona Zambrano, M. "La Tumba de Antígona” en Senderos, op.cit., p. 218.

11 Zambrano, M. Pensamiento y poesía en la vida española, Ed. Endymion, Madrid, 1987, p. 38.

12 Ibidem, p. 40.

13 Zambrano, M. El sueño creador, Madrid, Turner, 1986, p. 53.

14 Ibídem, p. 60.

15 Zambrano, M. "Sobre el problema de ser hombre” en La Torre, (San Juan de Puerto Rico), 1955, n 12, octubrediciembre. 
de una vida buena. Pues el hombre es criatura inacabada y su humanización procede de la aceptación y disposición a dejarse realizar por la obra que el Creador ha comenzado en él.

Le ha entregado el Señor al hombre algo muy suyo, el hacer, el haber de hacer. Mas a partir de todo lo que constituye el universo y del universo mismo. Criatura inacabada el hombre que tiene que valerse a solas bajo la ocultación la sombra del "Dios del trabajo"16.

Además María Zambrano da razón de este diálogo entre cuerpo y alma explicando que no estamos solos, radical diferencia de la filósofa con Heidegger, sino que tenemos un origen en el Creador y esta relación constituye a la persona, le hace persona y da sentido a sus vivencias en todas sus dimensiones

El místico norteño es un hombre solo, que en su absoluta soledad no es ni padre ni hijo, ni tal vez hermano de nadie; el místico del norte está en la filosofía, en la angustiosa filosofía idealista que tiene en ellos con toda seguridad, su raíz ${ }^{17}$.

Cuando María Zambrano escribe Pensamiento y Poesía en la vida española (1939) está tratando temas de intensa actualidad, como es la relación entre filosofía y poesía. Pero hemos ido viendo que esta razón filosófica es también ontológica y va uniendo filosofía y cuerpo con poesía y alma o don. Su pensamiento original y rompedor defiende una razón que está atenta y abierta a la realidad, cuidadosa, compasiva y nunca violenta. La violencia proviene de la soberbia de la razón. Esta soberbia se alía con el racionalismo, que es la afirmación de una razón encerrada en sí misma. La humildad, sin embargo, busca relacionarse y promueve el carácter filial que se sabe también fraterno.

Nada más infecundo que la rebeldía, aquella que mantiene al hombre suelto, ensimismado, sin hondura, confiado, en la miseria del aislamiento, que algunos se empeñan en llamar libertad o independencia, que algunos otros llegan hasta a llamar poderío, pero que es sólo miseria ${ }^{18}$.

La soberbia es contraria al amor. En El hombre y lo divino escribe páginas bellísimas acerca de la relación poesía y filosofía, que, como vamos viendo es trasunto, de una relación más propia de la condición humana, la existente entre el cuerpo y el alma, la relación entre lírica y razón. El amor nunca enajena, realiza y entraña al ser humano en un camino con futuro y con trascendencia, mientras que la sola razón lleva a la deriva, aliena al hombre y lo empobrece.

Cuando el hombre y las cosas tienen un ser desligado, que se cree bastarse a sí mismo, entonces se convierten en meros hechos, y la filosofía desaparece ${ }^{19}$.

16 Zambrano, M. "El Libro de Job y el pájaro" en El hombre y lo divino, Madrid, FCE, p. 366.

17 Zambrano, M. Pensamiento y poesía en la vida española, op. cit., p. 40.

18 Ibidem, p.

19 Zambrano, M. "Para una historia del amor" en El hombre y lo divino, op.cit., p. 253. 
En El hombre y lo divino se trata, entre otros, en dos bellos artículos de unos padeceres o sentimientos con fino análisis: Las ruinas y El infierno terrestre: la envidia donde se pone en evidencia que cuando se asume y se domina el cuerpo se vive en plenitud dicha relación cuerpo y alma, y que la vida es una bella tarea por hacer donde la libertad consiste en elegir siempre lo mejor, el mayor bien.

Así, las ruinas vienen a ser la imagen acabada del sueño que anida en lo más hondo de la vida humana, de todo hombre: que al final de sus padeceres algo suyo volverá a la tierra a proseguir inacabablemente el ciclo vida-muerte y que algo escapará liberándose quedándose al mismo tiempo, que tal es la condición de lo divino ${ }^{20}$

Zambrano considera que la reflexión sobre el cuerpo es puerta que abre a la condición del ser humano como ser relacional.

En Poema y sistema (1944) defiende, de nuevo, que la razón humana es unitiva, es decir, busca relacionarse con lo otro. "Religión, Poesía y Filosofía han de ser miradas de nuevo por una mirada unitaria" ${ }^{21}$. Y esta mirada unitaria integra la poesía que es don y a la filosofía que es pregunta sobre lo real, asume la vida en su razón cotidiana, no trata sólo la unidad del cuerpo y de la gracia (Simone Weil), sino que esa relación es mediadora horizontal y trascendentalmente, por ello busca modelos, busca padres que le proponga ejemplaridad de conductas y de ideas.

Así, Zambrano expone la aportación de Freud a la historia del pensamiento basada en su reflexión sobre el cuerpo y su interacción con la psique humana, pero rechaza su fijación en la libido porque es una "fuerza oscura y ciega. Y como ciega, trágica, profundamente trágica", lo cual constituye una interpretación reductiva de la energía de amor que es potenciadora de la conducta humana. En El freudismo, testimonio del hombre actual (1940) resalta como, posteriormente, escribirá también en su obra El pensamiento vivo de Séneca (1944) la necesidad de tener modelos de conducta, de reconocer a un padre, pues son los mediadores que dan vida y plenitud a la cultura. Y subraya que el reconocimiento del padre, engendrador de vida, nos permite amar y reconocer el propio cuerpo y sentirnos en una familia, que nos aporta un nombre mediante el cual podemos reconocer un sentido a la vida humana.

Nada más decisivo en una vida que sus propios orígenes. Por ello el padre es más que un hombre de carne y hueso que nos ha engendrado. Nos da un nombre. Mientras nuestra vida individual dure estará sellada por este nombre. Por él salimos de ser uno para ser alguien determinado ${ }^{22}$.

Es más, Zambrano exalta con claridad la necesidad de este reconocimiento para vivir un desarrollo emocional y cognitivo, y recuerda que este sentirse protegido por el amor paterno o materno es un patrimonio, una riqueza en forma de esperanza y de confianza para toda vida humana pues constituye un punto de partida necesario y potente. Este reconocimiento supone, además, una responsabilidad, pero también como recuerda Wojtyla, una humildad

20 Zambrano, M. "Las ruinas" en El hombre y lo divino, op.cit., p. 238-239.

21 Zambrano, M "Poema y sistema" en Hacia un saber sobre el alma, Madrid, Alianza Editorial, 1986, p. 47

22 Zambrano, M "El freudismo, testimonio del hombre actual” en Hacia un saber sobre el alma, op.cit., p. 119. 
Responsabilidad histórica y responsabilidad también, ante algo más difícil de nombrar; conciencia de nuestra limitación, de que hemos sido engendrados. Humildad ante el origen ${ }^{23}$.

La mirada de Zambrano sobre Freud le permite expresar una reflexión que le es querida, que la vida humana se desarrolla emocionalmente cuando se vive en confianza, se da crédito a los demás, y esta experiencia nace y se arraiga en el amor como principio que guía los primeros pasos. La filosofía del ejemplo ${ }^{24}$, la razón mediadora representada en la paterni$\operatorname{dad}^{25}$, la guía son los modelos que propone para entender y hacerse entender que ésta es la vida humana, de la cual a fuerza de pensar y de sentir, ella misma se constituye en ejemplo de vida y de pensamiento.

Por qué se escribe y La confesión hablan del sentir originario que es venir de Alguien, porque ahí radica este padecer la trascendencia que permite poner nombre al paraíso perdido de donde se procede y del que se siente siempre nuevas resonancias. Porque en este sentir se aúnan los sentidos, la sensibilidad sensorial y el sentimiento y, sin duda, la razón y el pensamiento. El cuerpo que reclama su algo más que es ya espiritual.

Ganar el nous sin perder el alma, adentrarse en la libertad cuanto nos sea posible sin aniquilar ni humillar la vida de las entrañas ${ }^{26}$.

En La confesión medita también sobre la paternidad y afirma que el ser humano busca la coincidencia de una vida consigo misma, pero siempre a través de Alguien porque la persona busca una identidad, que no sea abstracta ni cosificadora, sino quiere hallar el encuentro con Alguien que es la esperanza en un Ser Absoluto, el cual siendo otro, no enajena sino que entraña y realiza y da plenitud al ser humano ${ }^{27}$.

En el artículo que trata la naturaleza del amor, Para una historia del amor, avanza más y afirma que no sólo el cuerpo evoca y se comunica con el alma, sino que llama también a lo divino, dice:

el amor aparece en ese instante de revelación en que el hombre descubre que el mundo, tal como le es visible, que la naturaleza que él ha encontrado moviéndose en un ciclo fijo, no ha sido siempre así, sino que es la obra de alguien o de algo ${ }^{28}$.

23 Zambrano, M "El freudismo, testimonio del hombre actual” en Hacia un saber sobre el alma, Madrid, Alianza Editorial, 1987, p. 120.

24 Zambrano es filósofa de la crisis y le atribuye a su existencia a la falta de ejemplaridad, por eso piensa que de la crisis se sale admirando y dejándose contagiar por las conductas ejemplares, hay que saber mirar la realidad y decir la verdad.

25 Antonio Machado es considerado por Zambrano como Zambrano, M "La Guerra de Antonio Machado" en Senderos, Barcelona, Anthropos, 1986, p. 60-73.

26 Zambrano, M "Eloísa o la existencia de la mujer" en $S U R$, febrero, 1945.

27 Sánchez-Gey Venegas, J. "La filosofía como autobiografía: la confesión en María Zambrano" en VV.AA. Raices de la cultura española, Madrid, Fundación Fernando Rielo, 2004, p. 149-158.

28 Ibidem, p. 263. 
El sentir originario es un tema básico en el pensamiento religioso y en el ontológico de Zambrano. Así hablar del alma, del padecer, de la vocación, todos ellos serán los temas que se recuperan en el "sentir originario", la filosofía entonces se hace más humana y más divina.

"Razón poética que es, al par, metafísica y religiosa"29.

\section{Bibliografía}

Abellan, José Luis (2006): Una pensadora de nuestro tiempo, Anthropos, Barcelona.

VV.AA. (2004): Raíces de la cultura española, Fundación F. Rielo, Madrid.

Zambrano, María (1986): Hacia un saber sobre el alma, Alianza, Madrid.

Zambrano, María (1986): El sueño creador, Turner, Madrid.

Zambrano, María (1987): Pensamiento y poesía en la vida española, Endymion, Madrid.

Zambrano, María (1986): Senderos, Anthropos, Madrid.

Zambrano, María (1991): El hombre y lo divino, Siruela, Madrid.

Zambrano, María (1992): Los sueños y el tiempo, Siruela, Madrid.

29 Zambrano, M. El sueño creador, op. cit., 1986, p. 77. 